\title{
PROBLEME VON GRENZRÄUMEN UND PERSPEKTIVEN GRENZÜBERSCHREITENDER ZUSAMMENARBEIT AUS MITTELEUROPÄISCHER SICHT
}

B. M ülle r, I. R o c h: Problémy pohraničí a perspektivy přeshraniční spolupráce ze středoevropského pohledu. - Geografie - Sborník ČGS, 107, 4, pp. 383 - 395 (2002). Němečtí autoři přicházejí s pohledem „zvenči“ na problematiku pohraničí a přeshraniční spolupráce, a to na úrovni středoevropské a česko-německé. $\mathrm{V}$ obecné části vycházejí $\mathrm{z}$ všeobecně známého Martinezova modelu. Předpokládají, že s ohledem na rozšíření Evropské unie dojde $\mathrm{k}$ nárůstu významu pohraničí. Mezi aktéry přeshraniční spolupráce a příslušné struktury - vždy s odpovídající funkcí - patří na jednotlivých řádovostních úrovních: celostátní instituce, euroregiony, rozvojové agentury, obce, jakož i rủzná sdružení (spolky), firmy či iniciativy. Dále jsou analyzovány zkušenosti z česko-německého pohraničí, kde jsou využívány programy Interreg a Phare CBC. Nejvíce realizovaných projektů se řadí do cestovního ruchu a ekonomického rozvoje, územně se koncentrují do Euroregionu Nisa. V sousedských vztazích lze definovat pozitivní, ale i negativní aspekty. Zlepšení v této oblasti je navrhováno prostřednictvím opatření („stavebních kamenư“) jako předškolní výchova, školní vzdělávání, další vzdělávání pedagogů, hospodářské podniky, práce s veřejností). Tím bude dosaženo perspektivního cíle: decentralizované kooperace a vytvoření zóny ekonomické integrace.

KLÍCOVÁ SLOVA: česko-německé pohraničí - Euroregion Nisa - přeshraniční spolupráce - střední Evropa.

\section{Typen von Grenzräumen und die Bedeutung von Grenzräumen in der europäischen Politik}

Grenzräume zwischen Staaten sind oftmals durch ein großes $\mathrm{Maß}$ an Heterogenität geprägt. In Grenzräumen treffen unterschiedliche gesellschaftliche, wirtschaftliche, politisch-administrative und rechtliche Systeme direkt aufeinander. Grenzen markieren unterschiedliche sozio-ökonomische Ausgangsbedingungen, unterschiedliche Sprache und Kultur sowie vielfach auch verschiedene Geschwindigkeiten im Strukturwandel und in ökonomischen Entwicklungsprozessen.

In der wissenschaftlichen Diskussion und in der praktischen Politik werden Grenzräume als eine eigenständige Raumkategorie angesehen. Ihre Strukturen und Entwicklungsprozesse sind wesentlich von Staatsgrenzen geprägt. Diese spiegeln in ihrer Funktionsweise die vielfältigen Außenbeziehungen der jeweiligen Staaten wider. Ihre Auswirkungen auf die räumliche Interaktion und die Raumentwicklung hängen stark davon $a b$, ob es sich um „geschlossene“ oder „offene" Grenzen handelt.

Martinez (1994, 2ff.) unterscheidet in dieser Hinsicht vier Typen von Grenzregionen, die auch als Entwicklungsstufen der sozio-kulturellen und ökonomischen Integration in Grenzräumen bezeichnet werden können: 
- In entfremdeten Grenzregionen (alienated borderlands) besteht keinerlei Kontakt zwischen den Teilregionen und den Akteuren beiderseits der Grenzen. Hier kommt es zu deutlichen Abgrenzungen - teilweise sogar Abschottung - voneinander.

- Koexistierende Grenzregionen (co-existent borderlands) sind durch Öffnung gekennzeichnet, es kommt jedoch (noch) nicht zu einer wirklichen $\mathrm{Zu}$ sammenarbeit zwischen den Teilregionen beiderseits der Grenze.

- Anders ist dies in kooperierenden Grenzregionen (interdependent borderlands), in denen die jeweiligen Akteure über die Grenzen hinweg in mehr oder weniger intensive Kooperationsbeziehungen unterschiedlichster Art eingebunden sind.

- Hiervon werden wiederum vollständig integrierte Grenzregionen (integrated borderlands) unterschieden, in denen sich die Akteure und insbesondere die Bevölkerung aufgrund der Erfahrungen einer länger andauernden Zusammenarbeit über die Grenzen hinweg als Teil einer gemeinsamen grenzüberschreitenden Gesellschaft ansieht.

Wenn wir an dieser Stelle von Grenzregionen in Mitteleuropa sprechen, so sprechen wir von Räumen, in denen innerhalb eines kurzen Zeitraums von nur wenig mehr als 10 Jahren alle genannten Typen anzutreffen sind, die entfremdeten Grenzregionen beiderseits des ehemaligen „Eisernen Vorhangs", die koexistierenden Grenzregionen entlang von Staatsgrenzen mit deutlich unterschiedlichen gesellschaftlichen Strukturen und Entwicklungsvorstellungen, die kooperierenden Grenzregionen, etwa in den nach der Wende entstandenen Euroregionen entlang der Außengrenze der Europäischen Union, und die integrierten Grenzregionen, die sich durch das allmähliche Zusammenwachsen von Ost und West insbesondere in Deutschland herausgebildet haben oder herausbilden.

Gleichwohl ist unser Blick im Folgenden vor allem auf kooperierende Grenzregionen gerichtet. Sie werden in Zukunft in einer erweiterten Europäischen Union eine zunehmend wichtige Rolle spielen wie im Zuge der geplanten Erweiterung der Europäischen Union nach Mittel-, Ost- und Südosteuropa die Bedeutung von Grenzräumen auch insgesamt zunehmen wird. Dies lässt sich an zwei Zahlen belegen: Gegenwärtig leben lediglich 15 Prozent der Einwohner der jetzigen EU in Grenzräumen. In den Beitrittsstaaten sind es hingegen 62 Prozent der Einwohner. Damit wird der Anteil der EUBevölkerung, die in Grenzräumen lebt, in den nächsten Jahren deutlich ansteigen. Es ist zu erwarten, dass Fragen der Kooperation in Grenzräumen in der Zukunft auch ein größeres Gewicht in der öffentlichen Diskussion haben werden als bisher, denn bei Grenzräumen handelt es sich um Nahtstellen eines zusammenwachsenden Raumes, dessen Integrationsfähigkeit und innere Kohäsion wesentlich von der Funktionsfähigkeit der Grenzräume abhängt.

Dass Grenzräume - und zunehmend solche an den Außengrenzen der EU - bereits bisher eine vergleichsweise hohe Aufmerksamkeit in Europa haben, zeigt sich an den Programmen INTERREG und PHARE/CBC, die der grenzüberschreitenden Kooperation dienen. Mit der Gemeinschaftsinitiative Interreg wird in ihrer Ausrichtung A die Umsetzung von gemeinsamen Entwicklungsstrategien benachbarter grenzüberschreitender Gebiete gefördert, die zur Entstehung grenzübergreifender wirtschaftlicher und sozialer Entwicklungspole führen sollen. Innerhalb der Ausrichtung B (in der Förderperiode II: Ausrichtung C) wird die transnationale Zusammenarbeit zwischen nationalen, regionalen und lokalen Behörden gefördert, um die räumliche Integration innerhalb der Union anhand großräumiger Zusammenschlüsse eu- 
Tab. 1 - Finanzvolumen Interreg und Phare CBC

Interreg

\begin{tabular}{|l|c|c|c|}
\hline Förderperiode & I (1990-1993) & II (1994-1999) & III (2000-2006) \\
\hline Finanzvolumen / Förderperiode & 1032 Mio. EUR & 3519 Mio. EUR & 4875 Mio. EUR \\
\hline
\end{tabular}

Phare CBC

\begin{tabular}{|l|c|c|}
\hline Zeitraum & $1994-1999$ & $2000-2003\left(-2006^{*}\right)$ \\
\hline Finanzvolumen / Zeitraum & 1215 Mio. EUR & 652 Mio. EUR (+ 489 Mio. EUR*) \\
\hline
\end{tabular}

- hierbei handelt es sich um indikative Zahlen

* Das Finanzvolumen für die Jahre 2004 bis 2006 ist abhängig vom Erweiterungsprozess, da die betreffenden Staaten nach dem Beitritt zur EU über Interreg förderwürdig sind und nicht mehr über Phare, so dass zu erwarten ist, dass das Finanzvolumen für die jeweiligen Jahre weniger als die vorgesehenen 163 Mio. EUR umfassen wird.

Quellen: http://europa.eu.int/comm/regional_policy/interreg3/index_de.htm; http://europa.eu.int/comm/enlargement/pas/phare/. Europäische Kommission 27. 08. 2002: schriftliche Auskunft.

ropäischer Regionen voranzutreiben. Phare CBC wurde 1994 eingeführt, um die Kooperation zwischen den Grenzregionen Mittel- und Osteuropas mit angrenzenden Grenzregionen der EU bzw. mit benachbarten Grenzregionen anderer mittel- und osteuropäischer Staaten zu fördern. Insgesamt wurden seit 1994 rund 2,4 Milliarden Euro innerhalb von Phare CBC für Kooperationsvorhaben zur Verfügung gestellt, innerhalb von Interreg rund 9,4 Milliarden Euro - mit einem Zeithorizont bis 2006 (Tab. 1).

\section{Akteure und grenzübergreifende Kooperationsstrukturen in den Grenzräumen Mitteleuropas}

Bei den Grenzräumen an den Außengrenzen der Europäischen Union zu den Staaten Mittel- und Osteuropas (so auch besonders im tschechisch-deutschen Grenzgebiet) handelt es sich um Räume, in denen die jeweiligen Gesellschaften einer grundlegenden Systemtransformation von planwirtschaftlichen $\mathrm{zu}$ marktwirtschaftlichen Verhältnissen mit sehr unterschiedlichen Ausgangsvoraussetzungen und Ausprägungen unterliegen. Die vorherrschenden ökonomischen, sozialen und ökologischen Entwicklungsziele bilden in der Regel wesentlich schärfere Konfliktstrukturen aus als in den übrigen - von dem gesellschaftlichen Systemwechsel weniger oder nur mittelbar betroffenen - Regionen Europas.

Dies ist angesichts der Heterogenität dieser Grenzräume, ihrer Randlage gegenüber den politischen und wirtschaftlichen Zentren in der Europäischen Union und der speziellen räumlichen Entwicklungsprobleme einerseits ein Nachteil. Gleichwohl bietet sich hier andererseits aber auch die Chance, durch grenzüberschreitendes Handeln den EU-Integrationsprozess regional fortzuführen. Grenzraum wird damit zum „Vermittlungsraum“ (Müller et al. 2000). Der Umgang mit den unterschiedlichen Strukturen sowie das Erkennen von neuen Handlungsfeldern und Aktionsmustern kann die Herausbildung einer grenzüberschreitenden regionalen Identität fördern. Dafür bedarf es Schlüsselpersonen insbesondere auf der regionalen und lokalen Ebene. 
Eine wichtige Rolle spielen in dieser Hinsicht die Euroregionen, welche die Zusammenarbeit entlang der Grenzen auf regionaler Ebene gestalten. Sie haben - untersetzt durch ihre Facharbeitsgruppen - eine Organisations- und Bündelungsfunktion im Hinblick auf die unterschiedlichen Felder der grenzüberschreitenden Kooperation. Daneben spielen die Regionalen Planungsund Entwicklungsstellen bzw. - agenturen eine Rolle. Ihnen kommt - im unterschiedlichen Maße auf deutscher und tschechischer Seite eine Ordnungsund Entwicklungsfunktion zu. Während die Regionalplanung auf deutscher Seite zunächst überwiegend Aufgaben der Raumordnung erfüllte und erst sich erst langsam, unterstützt durch entsprechende Initiativen der Landesregierungen, der Regionalentwicklung öffnet, ist die Aufgabe, die regionale Entwicklung zu fördern und diese in ein regionales, insbesondere auch raumordnerisch orientiertes Konzept einzubinden, geradezu Gründungsauftrag der regionalen Entwicklungsagenturen in der Tschechischen Republik.

Hinzu kommen als Schlüsselakteure die jeweiligen staatlichen - insbesondere nationalstaatlichen - Stellen, einschließlich von Fachbehörden, die den Rahmen für die grenzüberschreitende Zusammenarbeit definieren. Zum Beispiel sind in Deutschland Grenzfragen Bundesangelegenheit, die Grenzraumförderung wird wesentlich durch die Länder bestimmt. Die Regelungen, die von ihnen vereinbart und implementiert werden, zum Beispiel im Hinblick auf den Umfang der Delegation von Kompetenzen, regional und lokal auf direktem Wege miteinander zu kooperieren und auch die finanziellen Vorkehrungen hierfür in eigener Verantwortung zu treffen, haben einen entscheidenden Einfluss auf die Intensität und Funktionsfähigkeit der Zusammenarbeit in Grenzräumen insgesamt.

Auf der lokalen Ebene sind es die Kommunen im Grenzraum selbst, welche die Kooperation innerhalb des gesetzten äußeren Rahmens gestalten können. Ihre Potentiale für die Herausbildung einer eigenen Identität in Grenzräumen und bei der Gestaltung von gesellschaftlichen Lernprozessen, welche die Denk- und Handlungsmuster der Entscheidungsträger und der Einwohner positiv verändern, ist unbestritten. Eine grenzüberschreitende interkommunale Kooperation (vgl. Scott in: Roch/Scott/Ziegler 1998) kann dabei endogene Entwicklungspotentiale $\mathrm{zu}$ Tage fördern sowie eine eigenständige und selbstbestimmende Regionalentwicklung unterstützen, die auf kleinräumige grenzüberschreitende Wirtschaftskreisläufe und Wertschöpfungsketten $a b$ zielt.

Dies gelingt in der Regel allerdings nur dann, wenn die Initiativen von Politik und Verwaltung eine Entsprechung im privatwirtschaftlichen und zivilgesellschaftlichen Bereich finden. Hierbei geht es einerseits um Firmen im Grenzraum bzw. ihre Verbände und ihre Bereitschaft und Fähigkeit, die Potentiale einer grenzüberschreitenden Zusammenarbeit $\mathrm{zu}$ erkennen und $\mathrm{zu}$ nutzen. Gleichwohl ist anzumerken, dass man in dieser Beziehung deutlich zwischen real existierenden Vorteilen und Wunschvorstellungen unterscheiden muss. Nicht immer entsprechen sich die wirtschaftlichen Potentiale beiderseits der Grenze oder legen ihre engere Verknüpfung im „engeren“ Grenzraum nahe. In diesen Fällen sind daher insbesondere die indirekten Auswirkungen, etwa auf den Arbeitsmarkt und die Kaufkraft in einer Grenzregion, sowie die vielfältigere und damit auch krisensicherere Einbindung eines Grenzraums in die sich zunehmend globalisierenden Wirtschaftsverflechtungen von Bedeutung.

Grenzüberschreitende Zusammenarbeit ist schließlich in ganz entscheidendem Maße auf Initiativen im zivilgesellschaftlichen Bereich angewiesen. 
Es waren und sind vielerorts gerade lokale, privat organisierte Initiativen, welche die Zusammenarbeit über Grenzen hinweg initiieren, strukturieren und tragen. Sie sind auch dann entscheidend, wenn Kooperationen zwischen öffentlichen Trägern zu erlahmen drohen oder auf institutionelle und formalrechtliche Hindernisse treffen. Sie gestalten die Vielfalt der Zusammenarbeit und haben großen Einfluss auf die lokalen Denk- und Handlungsmuster. Sie können die Herausbildung einer grenzüberschreitenden regionalen Identität und die Bereitschaft der Menschen, die Handlungszwänge und die Interessen der jeweiligen Nachbarn zu erkennen und zu verstehen, positiv unterstützen. $\mathrm{Ob}$ ein Grenzraum zum „Vermittlungsraum" wird, ist in erster Linie von ihnen abhängig.

\section{Erfahrungen mit grenzüberschreitender Zusammenarbeit am Beispiel des tschechisch-deutschen Grenzraums}

Inhaltliche Ansatzpunkte einer grenzüberschreitenden Kooperation bestehen - gerade auch im tschechisch-deutschen Grenzraum - grundsätzlich in allen Handlungsfeldern des öffentlichen und privaten Sektors. Gleichwohl hat sich in der Vergangenheit gezeigt, dass es hier in einzelnen Grenzräumen oder Grenzraumabschnitten unterschiedliche Schwerpunkte und Handlungsansätze gibt (vgl. Tab. 2).

Tab. 2 - Anzahl genehmigter Projekte nach Maßnahmengruppen in ausgewählten Grenzregionen der östlichen EU-Außengrenze, INTERREG II (Roch/Scott/Ziegler 1998, s. 28)

\begin{tabular}{|l|rr|c|c|c|c|c|c|}
\hline Maßnahmengruppe & Elbe Neiße & Erzgebirge & Egrensis & $\begin{array}{l}\text { BRD - } \\
\text { CR }^{2)}\end{array}$ & $\begin{array}{l}\text { BRD - } \\
\text { Polen }\end{array}$ & $\begin{array}{l}\text { BRD - } \\
\text { Polen } \\
- \text { CR }^{2)}\end{array}$ & $\begin{array}{l}\text { Summe der } \\
\text { Projekte }\end{array}$ \\
\hline Verkehr & 4 & 9 & 2 & 1 & - & - & - & 16 \\
Technische Infrastruktur & 4 & 9 & 1 & 2 & - & - & 1 & 17 \\
Davon ${ }^{1)}$ & 1 & 7 & 1 & 2 & - & - & - & 11 \\
Soz. Infrastr./Bildung & 6 & 5 & 1 & 1 & - & - & - & 13 \\
Umwelt & 2 & 1 & - & - & 4 & 1 & 1 & 4 \\
Wirtschaftl. Entw. & 6 & 6 & 1 & 3 & - & - & 3 & 24 \\
Tourismus & 13 & 28 & 9 & 5 & - & - & 2 & 57 \\
Humanressourcen & 4 & 2 & - & 1 & - & - & - & 7 \\
Katastrophenschutz & - & - & - & - & - & - & - & - \\
Gesamt & 39 & 60 & 14 & 13 & 4 & 1 & 7 & 138 \\
\hline
\end{tabular}

1) Projekte, deren Inhalt sich mit Fragen des Abwassers beschäftigt

${ }^{2)}$ Diese Projekte wirken nicht nur grenzraumbezogen, sondern landesweit Quellen:

1. Regierungspräsidium Dresden, "INTERREG II genehmigt", 19.06.1997

2. Sächsisches Staatsministerium für Wirtschaft und Arbeit Dresden, "GI INTERREG IIProjektliste 1996", Liste der bewilligten Projekte - Teil EFRE, Stand 31.12.1996

3. Euroregion Elbe/Labe, Kommunalgemeinschaft Euroregion Oberes Elbtal/Osterzgebirge e. V. Pirna, "Projekte im Rahmen des Förderprogramms INTERREG II 1995/96"

4. Veranstaltung "Heilbäder und Kurorte in Europa - Möglichkeiten und Chancen einer verstärkten Kooperation der Grenzregionen"; Tourismus - Know-how-Transfer in Euroregionen 
Im böhmisch-sächsischen Grenzraum sind es nach wie vor die weichen Kooperationsfelder, auf die sich lokale und regionale Aktivitäten konzentrieren. Hierzu gehören die Zusammenarbeit in den Bereichen Kultur, Sport und Fremdenverkehr. Hinzu kommen in einer Vielzahl von Gemeinden Kontakte und gemeinsame Projekte im Bildungsbereich. In den Bereichen Infrastruktur und Umwelt sind insbesondere Fragen der regionalen und örtlichen Wasser-, Abwasser-, Gas- und Stromversorgung sowie der Telekommunikation von Interesse. Bei erfolgreichen Infrastrukturvorhaben handelt es sich um den Bau von Kläranlagen und Abwasserkanalisationen, denn gerade in diesen Bereichen ist angesichts des gestiegenen Umweltbewusstseins und entsprechender nationaler und internationaler Regelungen der Handlungsdruck vor Ort sehr groß.

Hinzu kommen Fragen des grenzüberschreitenden Verkehrs. Die Entwicklung grundlegender Transportinfrastrukturen, d.h. die Schließung von Lücken oder Engpässen in den Verkehrsnetzen, die Einrichtung von Grenzübergängen und die Anbindung an internationale Infrastruktur- und Kommunikationsnetze, gehört zu den Hauptaufgaben in den Grenzgebieten.

Untersuchungen zeigen, dass Kooperationsansätze in Grenzräumen - gerade auch in der Anfangszeit - von räumlicher Nachbarschaft beruhen. In einer Befragung im böhmisch-sächsischen Grenzraum (Müller et al. 2000) wurde Ende der neunziger Jahre festgestellt, dass 70 Prozent der Gemeinden, in denen eine grenzüberschreitende Kooperation entstanden war, unmittelbar an der Grenze lagen. Die räumliche Nachbarschaft und die enge historische Verbindung von Gemeinden impliziert ähnliche Problemstrukturen sowie gleichzeitig Potenziale für Lösungsansätze. In den direkt an der Grenze liegenden Gemeinden zieht man dabei die hauptsächliche Motivation zur $\mathrm{Zu}-$ sammenarbeit vielerorts eher aus einem konkreten Problemdruck als aus diffusen und relativ vagen Entwicklungserwartungen. Teilweise will man dabei auch die Nachteile der Grenzlage gemeinsam überwinden. Mit Blick auf nationale und internationale Förderprogramme wie auch auf die steigende Bedeutung einer europäischen Integration werden Grenze und Grenzlage zu einem „unique selling product“, mit dessen Hilfe sich ein nicht unerheblicher Fluss an finanziellen Mitteln in den Grenzraum hinein lenken lässt.

Gleichwohl sind in diesem Zusammenhang nicht unerhebliche Kooperationshindernisse und -hemmnisse in Grenzräumen $\mathrm{zu}$ beachten (vgl. Roch/Scott/Ziegler 1998, S. 43 ff.): Hierzu gehören zum einen erhebliche Asymmetrien im institutionellen Gefüge. Rechtssysteme sind unterschiedlich, Verwaltungsgrenzen und - gliederungen sind nur bedingt kompatibel, Verwaltungsstrukturen und Zuständigkeiten variieren beiderseits der Grenze, politische Gremien und ihre Kompetenzen weisen häufig nur eine geringe Passfähigkeit auf.

Ungünstige sozioökonomische Rahmenbedingungen, hohe Arbeitslosigkeit, unsichere Zukunftsperspektiven und ein Wirtschaftsgefälle zwischen Teilräumen stellen einen äußerst sensiblen Bereich dar. Sie bieten den Nährboden für „Kirchturmpolitik“, Konkurrenzdenken und Abwehrreaktionen. Wirtschaftliche Existenzängste dominieren die Stimmungsbilder. Die desolate Finanzlage vieler Gemeinden begrenzt die Handlungsspielräume. Oft fehlen Zeit, Personal und finanzielle Mittel für freiwillige kommunale Aktivitäten.

Ein sensibler Bereich ist zudem die Frage der Freizügigkeit im Grenzraum. Zum einen wird die Öffnung von Grenzen allgemein begrüßt, zum anderen sieht man sich aber auch vor neuen Konflikten und Problemlagen. In diesem Zusammenhang werden vor allem einseitige Produktions- und Arbeitskraft- 
verlagerungen, eine Zunahme von Kriminalität sowie das punktuell erhöhte Verkehrsaufkommen in Grenzorten genannt. Es ist nur im konkreten Einzelfall abzuschätzen, inwieweit diese Einschätzungen auf realen Grundlagen basieren oder eine Reproduktion von Vorurteilen darstellen. Die ungünstigen Rahmenbedingungen lähmen die Kooperationsbereitschaft und die Innovationsfähigkeit von Regionen und drängen die Akteure in eine gewisse passive Empfängerhaltung. Auch wenn Entwicklungspotentiale vorhanden wären, würden sie daher nicht oder nur suboptimal genutzt.

Vor diesem Hintergrund laufen grenzüberschreitende Aktivitäten nicht selten in die falsche Richtung: Projekte werden auf kurzfristige und einseitige Erfolge ausgerichtet. Partnerschaften sind formaler Natur. Nicht selten kommen Projekte eher zufällig - ohne Bezug zu einer umfassenderen Entwicklungsvision - zustande. Aufgrund der drückenden Probleme verlieren Akteure leicht die Gesamtentwicklung aus den Augen. Damit geht jedoch ein Gefühl für die Chancen verloren, die in Grenzräumen bestehen und die durch grenzüberschreitende Kooperation besser genutzt werden könnten.

\section{Die nachbarschaftlichen Beziehungen im deutsch-tschechischen Grenzraum}

Ausgehend von den Erfahrungen der grenzüberschreitenden Zusammenarbeit auf der Projektebene und bei der Aufstellung und Umsetzung gemeinsamer Entwicklungskonzepte (Roch 1996; Roch/Scott/Ziegler 1998, S. 20 ff.) wurden im Auftrag des Bayerischen Staatsministeriums für Landesentwicklung und Umweltfragen Grundlagenuntersuchungen zum Stand und zu Perspektiven guter Nachbarschaft in den bayerisch-tschechischen Grenzräumen durchgeführt (Roch 2001). Untersucht wurden die Grenzräume der Euroregion Egrensis im Vergleich zum Bayerischen Wald/Šmava. Diese Untersuchungen bildeten die Basis für die Ableitung von Empfehlungen zu einem abgestuften und mehrgleisigen Vorgehen im Rahmen einer systematischen Förderung guter Nachbarschaftsbeziehungen. Aus wissenschaftlicher Sicht hinterfragten diese Untersuchungen die aktuelle Situation des Zusammenlebens der Grenznachbarn und speziell die Ursachen für Defizite neben positiven Ansatzpunkten. Ein besonderes Anliegen war die Ableitung verallgemeinerungsfähiger und raumspezifischer Verhaltensweisen und Motivationen.

Für die Untersuchungen wurden quantitative und qualitative Methoden der Sozialforschung genutzt. Das methodische Vorgehen beinhaltete die Arbeitsschritte a) Kontaktaufnahme mit Akteuren der Raumentwicklung in den Grenzräumen der Euroregionen Egrensis und Bayerischer Wald/Sumava sowie der jeweiligen Landratsämter, b) Auswahl der Experten für Expertengespräche und Studium von Dokumenten zur Vorbereitung dieser Gespräche, c) Befragung von Kindergartenkindern und Schülern der 8. Klassen von Realschulen und Gymnasien bei Einbeziehung einer Dolmetscherin und ausgebildeten Pädagogin im tschechischen Grenzraum, d) Befragung von Kindergärtnerinnen, Schulleitern, Fachlehrern, älteren Menschen und aktiv wirtschaftlichen Tätigen, e) Expertengespräche mit Vertretern der Wirtschaft und ausgewählten Persönlichkeiten der Politik, f) Diskussion erster Untersuchungsergebnisse mit den Vertretern der Euroregionen und mit dem Auftraggeber, anschließend Fertigstellung der Studie. 
Die Empfehlungen wurden als Bausteine definiert. Sie betreffen die Vorschulbildung, die Schulbildung, die Aus- und Weiterbildung von Lehrern, Erziehern und Kindergärtnerinnen sowie die Einbeziehung von Wirtschaftsunternehmen in die Förderung guter nachbarschaftlicher Beziehungen und nicht zuletzt die Weiterentwicklung der Öffentlichkeitsarbeit. Dabei reagieren die Empfehlungen zur Öfentlichkeitsarbeit sowohl auf Informationsdefizite und Schäden aus unseriöser Berichterstattung für die gegenseitige Verständigung als auch auf gute Beispiele der Berichterstattung im Rahmen der fachspezifischen Arbeit. In den Wirtschaftsunternehmen wurden mögliche potenzielle Partner hinterfragt, die für die Annäherung der Grenznachbarn von Bedeutung sein könnten über die Entwicklung gemeinsamer Perspektiven und über die Ausbildung des Nachwuchses. In den grenzübergreifend tätigen Unternehmen wurden Partner gesucht, die die gegenseitige Verständigung und ein schrittweises Miteinander in dem künftigen gemeinsamen Wirtschaftsraum mit voranbringen können.

Aus den Untersuchungsergebnissen wurden Thesen zur Förderung guter nachbarschaftlicher Beziehungen abgeleitet, die den einzelnen Analysebereichen zugeordnet wurden. Als besonders erfolgreich erweisen sich konkrete Maßnahmen im Bereich der Wirtschaft. Hier werden geradlinige Ziele angesteuert und Effekte erreicht zum gegenseitigen Nutzen. Die Argumentation liegt dabei im rationalen Bereich. Diese Aktivitäten erreichen potenzielle Akteure und motivieren künftige Führungskräfte, die für die Entwicklung des Teilraumes Erfolge bringen. Dadurch wird die Nachbarschaft und das Nachbarland interessant.

Der Schlüssel für die Annäherung der Grenznachbarn wird in der Zukunftsorientierung erkannt. Die Hilfestellungen der vergangenen Jahre und das pharisäerhafte Aufzählen von Für und Wider, auch gute bis vorbildliche Programme grenzüberschreitender Zusammenarbeit erweisen sich als weniger wirksam als eine gemeinsame Herausforderung für die arbeitsfähige und heranwachsende Generation. Dazu müssen Barrieren abgebaut werden und ein unkonventionelles aufeinander Zugehen möglich sein. Abwarten zahlt sich nicht aus, auch nicht zögerliches Zuschauen. Mit der natürlichen $\mathrm{Ab}-$ lösung der Nachkriegsgeneration bietet sich die Möglichkeit, die alten schwelenden Vorbehalte auf beiden Seiten über Bord zu werfen. Aufgebaut werden kann auf die eigenen Erfahrungen. Die hohe Motivation, der gute Bildungsstand und der beispielhafte Lerneifer der jungen tschechischen Generation kann sich mit den Erfahrungen und Kenntnissen in den Informationstechniken, im Management, zu Rechtsfragen und mit dem Investitionskapital auf der bayerischen Seite sinnvoll ergänzen. Über Erfolge der Kinder lassen sich Meinungen der Eltern schrittweise korrigieren.

Für die Annäherung der Grenznachbarn scheint die Zeit der Pioniere und Einzelkämpfer abgelaufen zu sein. Diesen Wegbereitern folgen gruppendynamische Prozesse der Gestaltung des Lebens- und Wirtschaftsraumes, getragen von einer jungen Generation künftiger Europäer. Diese Prozesse sollten von der Raumordnung aufgrund ihrer langjährigen praktischen Erfahrungen und wissenschaftlichen Forschungen als dynamische Integration vorbereitet und moderiert werden. Dabei sollte sich die Raumordnung insbesondere der Partnerschaften mit der Bildungs- und Wirtschaftspolitik versichern. Die Anbahnung guter nachbarschaftlicher Beziehungen kann sich als gemeinsamer Entwicklungs- und Lernprozess im regionalen Kontext gestalten, wobei Initiativen von fachlichen und kommunalen Handlungsbedarfen ausgehen können, die auf die Regionen oder auf die Stärkung funktionaler Beziehungen 
wirken. Insbesondere durch die Zusammenarbeit und Perspektiven auf dem Gebiet der Wirtschaft können Berührungsängste und das Besitzstandsdenken abgebaut und Chancen aktiv genutzt werden.

Für die Annäherung der Grenznachbarn empfiehlt sich ein vielschichtiges aber räumlich koordiniertes Vorgehen auf den Feldern der Bildung und Öfentlichkeitsarbeit, die von dem im Grenzraum aktiven Wirtschaftsunternehmen gefördert werden kann und durch gemeinsame Erfahrungen und Ziele eine Perspektive erhält. Die nachfolgenden Empfehlungen zur Förderung guter Nachbarschaft sind als Bausteine aufzufassen, wobei im gegenseitigen Kennenlernen, in der Unterstützung der Neugier auf den Nachbarn die Grundlage gesehen wird, auf der Vertrauen und Gemeinsamkeit wachsen können.

\section{Baustein Vorschulbildung}

- Kontaktanbahnung im Kindergarten

- Persönliche Begegnungen

- Austausch von Kindern

- Organisation gemeinsamer Wochenenden mit Unterkunft in Gastfamilien

- Nicht-Kindergartenkinder sind über Informationen der Kommunen einzubeziehen

Bedingungen: Abstimmung mit den Sozialämtern, Klärung der Sicherheitsbestimmungen, finanzielle Unterstützung der Begegnung, z. B. Fahrtkosten, Verpflegung

\section{Baustein Schulbildung}

- Informationen über das Nachbarland als Teil der Euroregion in der Unterstufe

- Fachliche Informationen, z. B. über die Fächer Heimatkunde, Kunsterziehung, Musik, Deutsch, Biologie, Geographie, Gesellschaftskunde ab der Mittelstufe

- Gemeinsame sportliche Aktivitäten und Wandertage

- Austausch bzw. Kontaktaufnahme von Lehrern und Elternräten

- Stiftung eines Zertifikats für nachbarschaftsbewusste Schulen z. B. durch das Kultus- und Landesentwicklungsministerium

Bedingungen: Absprachen zwischen dem Kultusministerium und der Landesentwicklung, ggf. auch mit der Euroregion, Fonds für die materielle Absicherung der Begegnungen

\section{Baustein Aus- und Weiterbildung für Lehrer, Erzieher und Kindergärtnerinnen}

- Einbindung der Lehrstoffe europäische Integration, Regionalentwicklung, Standortentwicklung, interregionale Kommunikation in die Lehrprogramme

- Kontaktanbahnung von Studierenden zwischen Bayern und Tschechien bei Einbeziehung von Sachsen und Thüringen

- Austauschpraktika bzw. Hospitationen als Pflichtauflage für den Einsatz in den Fächern Heimatkunde, Gesellschaftskunde, Geschichte, wahlweise für Biologie, Geographie,

- Musik, Kunsterziehung

Bedingungen: Absprachen mit den Wissenschaftsministerien, Klärung von Sicherheitsbedingungen, Anerkennung der Hospitationen bzw. Austausch- 
praktika, Einwirkung auf die Einstellungskriterien in Schulen bzw. auf die Verbeamtung durch Anerkennung der o. g. Bedingungen

\section{Baustein Wirtschaftsunternehmen}

- Bereitstellung von Informationen über wirtschaftliche Aktivitäten und Entwicklungsperspektiven der Euregio für das Lehrprogramm

- Aktuelle Medieninformationen und Videos über grenzübergreifende Aktivitäten von Unternehmen

- Prämierung von Unternehmen, die Jugendliche mit „Wanderjahr“ im Nachbarland einstellen

- Sponsoring der Unternehmen für Zusammenarbeit in den Kindergärten und Schulen

Bedingungen: Anbahnung eines Aktionsbündnisses zwischen der Euregio, den Unternehmen, den Schulen und Kindergärten, Honorierung vorbildlicher Aktivitäten von Unternehmen mit einem Zertifikat

\section{Baustein Öffentlichkeitsarbeit}

- Prämierung objektiver und aktueller Medieninformationen über die nachbarschaftlichen und grenzüberschreitenden Kontakte durch ein „Eurosie-

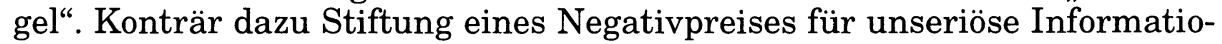
nen

- Einrichtung einer Jury aus Mitgliedern beider Länder zur Vergabe dieser Auszeichnungen

- Honorierung guter Öffentlichkeitsarbeit der Kommunen (wie oben)

- Honorierung vorbildlicher Aktivitäten von Privatpersonen einschließlich Lehrer, Eltern, Schüler, Studenten u. a.

Bedingungen: Eruierung möglicher Sponsoren für ein Preisgeld. Erarbeitung der Modalitäten für die Auslobung der Preise.

\section{Perspektiven: Dezentrale Kooperation und die Herausbildung einer Zone wirtschaftlicher Integration}

Die verstärkte grenzüberschreitende Zusammenarbeit in Mitteleuropa ist eine wichtige Voraussetzung für das Zusammenwachsen der europäischen Union. Sie hat eine Schlüsselfunktion für die Integration der Staaten, die in Kürze der Europäischen Union als neue Mitglieder angehören werden. Die Regionen beiderseits der Außengrenzen der heutigen EU - und damit insbesondere der Grenzen zwischen Tschechien und Deutschland - werden besonders gefordert sein, wenn die Integration der Beitrittsstaaten gelingen soll. Diese Regionen sind in hohem Maße unmittelbar von der Öffnung der Grenzen und den damit verbundenen Veränderungen der sozialen und ökonomischen Rahmenbedingungen betroffen.

Grenzüberschreitende Zusammenarbeit sollte vor diesem Hintergrund vor allem an drei Entwicklungsbarrieren ansetzen:

- den vorhandenen Strukturproblemen

- den politisch-administrativen Asymmetrien und den Unterschieden durch nationale Rechtssysteme sowie

- den unterschiedlichen Mentalitäten der Bevölkerung. 
Der unmittelbaren Zusammenarbeit zwischen den Akteuren auf der regionalen und der lokalen Ebene wird eine entscheidende Bedeutung für das Entstehen von integrierten Grenzräumen zukommen. Hierfür ist es allerdings erforderlich, dass diese Akteure sowohl diese Bedeutung erkennen als auch die Kompetenzen haben und in der Lage sind, miteinander auf direktem Wege zusammenzuarbeiten. Dies erfordert einerseits einen staatsvertraglichen Rahmen zur Stärkungen der Zusammenarbeit auf regionaler und lokaler Ebene und andererseits funktionsfähige Kooperationsstrukturen auf beiden Seiten der Grenze.

Die neu entstandenen bzw. sich weiter ausformenden regionalen Strukturen beiderseits der Grenze zwischen Tschechien und Deutschland bieten gute Voraussetzungen für die Zusammenarbeit. Die verstärkte Einbindung von Kommunen und Bürgern in regionale und lokale Entwicklungsprozesse begünstigen eine schnellere und größere Breitenwirkung des sozialen und ökonomischen Wandels. In der Zukunft wird es aber auch darauf ankommen, dass zunehmend auch die Wirtschaft in diese Kooperationen eingebunden ist. Erfolgreiche grenzübergreifende Kooperationen wirken sich durch ihre Ausstrahlungseffekte auf die Region aus und treiben die Bildung einer gemeinsamen regionalen Identität voran.

Es gibt bereits eine Reihe gut funktionierender grenzüberschreitender Kooperationen zwischen Firmen im Grenzraum, gleichwohl ist man in Mitteleuropa noch weit von der Entstehung eines gemeinsamen Wirtschaftsraums oder einer Zone wirtschaftlicher Integration entfernt. Die Durchlässigkeit der Grenze bestimmt den Güter- und Faktoraustausch. Komparative Kostenvorteile einer regional gebundenen grenzüberschreitenden Zusammenarbeit zwischen deutschen und tschechischen Firmen werden noch zu wenig erkannt.

Bisher ist keineswegs eindeutig zu sagen, wie der Integrationsprozess in einer erweiterten Europäischen Union die wirtschaftliche Situation in de Grenzregionen beeinflussen wird. Klein- und mittelständische Firmen sehen die Veränderungen teilweise eher skeptisch und erwarten - insbesondere auf der deutschen Seite - nur geringe bzw. eher negative Veränderungen aufgrund schärferen Wettbewerbs. Demgegenüber kann man annehmen, dass die Öffnung von Grenzen und geringere Kooperationshemmnisse die Intensivierung des internationalen Handels und eine internationale und interregionale Arbeitsteilung verstärken. Dies dürfte jedoch eher für die Zusammenarbeit zwischen den in der Regel eher grenzfern als grenznah gelegenen Räumen wirtschaftlicher Prosperität positive Auswirkungen haben. Es wird eine herausragende Aufgabe der Zukunft sein, die Weichenstellungen in der grenzüberschreitenden Zusammenarbeit - gerade auch in peripheren strukturschwachen Gebieten - so vorzunehmen, dass die Zusammenarbeit zur Herausbildung integrierter Regionen und zu einer nachhaltigen Verbesserung der Lebens- und Arbeitsbedingungen der dort lebenden Menschen führt. Internationale und interdisziplinäre Grenzraumforschung kann hierzu einen wesentlichen Beitrag leisten.

\section{Literatur}

MARTINEZ, O. J. (1994): The dynamics of border interaction. In: Schofield, D.H.: Global Boundaries. World Boundaries. Vol. 1. London, New York 1-15.

MÜLLER, B., KUCERA, K., JERABEK, M., PRIKRYL, J. (2000): Grenzraum als Vermittlungsraum. Chancen der interkommunalen Zusammenarbeit am Beispiel von Sachsen und Böhmen. Berlin. 
ROCH, I. (1996): Das Sächsische Vogtland im Dreiländereck Bayern-Böhmen-Sachsen. Ansätze einer umweltverträglichen grenzübergreifenden Entwicklung. Sonderheft des Instituts für ökologische Raumentwicklung e. V. (Hrsg.). Dresden.

ROCH, I.; SCOTT, J.; ZIEGLER, A. (1998): Umweltgerechte Entwicklung von Grenzregionen durch kooperatives Handeln. In: Institut für ökologische Raumentwicklung e. V. (Hrsg.). IÖR-Schriften 24. Dresden.

ROCH, I. (2001): Grundlagenuntersuchungen zur Förderung guter Nachbarschaft im bayerisch-tschechischen Grenzraum am Beispiel der Euregio Bayerischer Wald/Böhmerwald. Honorarauftrag des Bayerischen Staatsministeriums für Landesentwicklung und Umweltfragen München im Rahmen des Modellvorhabens „Förderung guter Nachbarschaft im bayerisch-tschechischen Grenzraum“. August 2001 (unveröffentlichtes Manuskript).

ROCH, I. (2001): Europas neue Grenzen: Abschottung oder Durchlässigkeit? Europa-Konferenz der Grünen Akademie „Moderne Zeiten, Europäische Räume - Grenzfragen“ vom 23. bis 25. Februar 2001. Berlin. Internetpräsentation.

\section{Shrnutí}

\section{PROBLÉMY POHRANIČÍ A PERSPEKTIVY PŘESHRANIČNÍ SPOLUPRÁCE ZE STŘEDOEVROPSKÉHO POHLEDU}

Příspěvek německých geografů/regionalistů z Institutu pro prostorový ekologický rozvoj (Institut für ökologische Raumentwicklung Dresden) seznamuje s problematikou pohraničí a přeshraniční spolupráce, a to na úrovni středoevropské a česko-německé. Je koncipován v logické posloupnosti od obecných (teoretických) záležitostí, přes sledování prostřednictvím statistických údajů po hodnocení subjektivního vnímání (prostřednictvím výsledků empirických šetření). Setkáváme se rovněž s akcentem praktické politiky resp. usměrňování socioekonomického vývoje a snaze odhalit (určit) budoucí vývoj v této oblasti. Článek je strukturován do pěti kapitol: Typy pohraničí a význam pohraničí v evropské politice, Aktéři a přeshraniční kooperační struktury v pohraničí střední Evropy, Zkušenosti s přeshraniční spoluprací na příkladu česko-německého pohraničí, Sousedské vztahy v česko-německém pohraničí, Perspektivy: decentralizovaná kooperace a vytvoření zóny ekonomické integrace.

Pohraničí se vyznačují často značnou mírou heterogenity. V obecné části vycházejí autor̆i z všeobecně známého modelu Martinezova (1994), kde definují pohraniční regiony jako odcizené, koexistující, kooperující a integrované. Připomínají, že situace ve střední Evropě se za posledních 10 let výrazně změnila, jakož i roli Německa. Předpokládají, že s ohledem na rozšíření Evropské unie do střední, východní a jihovýchodní Evropy dojde k nárůstu významu pohraničí. Zatímco v členských státech žije v pohraničních oblastech (zřejmě do 50 $\mathrm{km}$ od hranic) jen $15 \%$ obyvatelstva, v kandidátských zemích se jedná o $62 \%$. Od roku 1990 resp. 1994 slouži programy Interreg a Phare CBC, jejichž prostřednictvím byl vývoj v pohraničí podpořen do 2000 téměř 5,8 mld. EUR. V současné podpůrné periodě $(2000-2006)$ se počítá s obdobnou částkou.

Rozdíly na evropských hranicích způsobují zpravidla těžkosti. Na druhé straně je však možné tato území vnímat jako prostor zprostředkování, těžící (využívající) odlišnosti v pozitivním slova smyslu ke svému rozvoji. Vedle státní (národní) úrovně hrají dủležitou roli euroregiony, prričemž se uplatňuje především jejich organizační a propojující funkce. Za žádoucí je považována jejich spolupráce s regionálními rozvojovými (někdy také plánovacími) agenturami, které usilují o usměrňování regionálního a lokálního rozvoje. $\mathrm{Na}$ lokální úrovni se jako nezastupitelná jeví úloha obcí, a to především při vytváření vlastní (svébytné) identity pohraničí a využití endogenního potenciálu. Poslední př́iklad aktérů a přeshraničním kooperačních struktur představují nejrůznější instituce společenského a ekonomického života (sdružení, spolky, iniciativy, podniky apod.), u nichž se prosazuje především funkce motivační a tvůrčí. Právě tato skupina nejvíce působí na celkový charakter (vnímání) pohraničí.

Dále jsou analyzovány zkušenosti s přeshraniční spoluprací z česko-německého pohraničí, kde jsou využívány programy Eyropské unie Interreg (v členských státech) a Phare CBC (v kandidátských zemích resp. Česku). Nejvíce realizovaných projektů se řadí do cestovního ruchú a ekonomického rozvoje, významně se uplatňují rovněž kultura, sport a vzdělávání. Územně se koncentrují do Euroregionu Nisa, druhé místo v rámci česko-saského pohraničí patři mezi sledovanými oblastmi Euroregionu Elbe/Labe. Na úrovni obcí je 
častá spolupráce bezprostředně hraničních obcí. Rozšíření a prohloubení přeshraniční spolupráce omezuje značná asymetrie (nekompatibilita) v institucionální rovině, ale také konkurence a zdrženlivost podmíněná nepříznivou ekonomickou situací po obou stranách hranice. Můžeme také hovořit o nedostatku času, slabém personálním obsazení i malých finančních prostředcích.

Na zakázku bavorského ministerstva územního rozvoje a životního prostředí byla ve 2 . polovině 90 . let 20 . století realizována celá řada empirických šetření v euroregionech Egrensis a Šumava, jejichž záměrem bylo zjistit úroveň sousedských vztahů a následně stanovit cesty $\mathrm{k}$ jejich zlepšení (prohloubení). Skládala se z expertních rozhovorů, ankety s dětmi v mateřských školách a 8. třídách základních škol a jejich pedagogy, jakož i s ekonomicky aktivními osobami. Doporučení byla definována formou „stavebních kamenů“, přičemž za klíč pro přiblížení přeshraničních sousedů je považována orientace na budoucno. V komplexu Předškolní výchova lze zmínit např. osobní setkávání, výměnu dětí včetně společně prožitých víkendů. Pro Školní vzdělávání se ukazuje vhodné zařazení odpovídajících informací o druhé straně v řadě předmětů, jmenujme alespoň vlastivědu, geografii, biologii, uměleckou či hudební výchovu. V Dalším vzdělávání pedagogů se doporučuje mj. zařadit do učebních programů problematiku evropské integrace, regionálního rozvoje, výměnná praktika resp. hospitace ve vybraných předmětech. Blok Hospodářské podniky by se měl zaměřit na šíření informací o ekonomických aktivitách a rozvojových perspektivách př́íslušného regionu či ocenění podniků, které umožní mladým seznámení s konkrétním podnikem na druhé straně hranice. Mezi úkoly Práce s veřejností byla zařazena problematika sledování objektivních a aktuálních informací ve sdělovacích prostředcích včetně odměny těm obcím, institucím nebo jednotlivým osobám, které dosáhnou nejlepších výsledků.

Přeshraniční spolupráce je do určité míry podmíněna konkrétními překážkami, mezi něž se řadí: stávající strukturální problémy, politicko-administrativní asymetrie a rozdíly v legislativních systémech, jakož i rozdílná mentalita obyvatelstva. Úspěšná spolupráce působí pozitivně jako vzor pro ostatní dotčené v regionu a napomáhá vytváření regionální identity. Postupně by toto úsilí mělo směřovat $\mathrm{k}$ perspektivnímu cíli: decentralizované kooperaci a vytvoření zóny ekonomické integrace. V současnosti nelze zatím jednoznačně říci, zda a jak ovlivní předpokládané rozšiřování Evropské unie ekonomickou situaci v pohraničí. Dosud realizovaná mezinárodní spolupráce se totiž odehrává spíše na relativně velké vzdálenosti a spíše zřídka mezi subjekty ležícími v pohraničí. Jen touto cestou se ale mohou pohraniční regiony prosadit v konkurenci s ostatními vnitrozemskými regiony a zároveň zlepšit zdejší životní a pracovní podmínky. V tomto směru má mezinárodní a interdisciplinární výzkum pohraničí před sebou dostatek prostoru pro vědecké bádání i aplikaci získaných poznatků do praxe.

(Pracoviště autorũ: Institut pro prostorový ekologický rozvoj / Institut für ökologische Raumentwicklung e.V., Weberplatz 1, D-01217 Dresden, Německo; b.mueller@ioer.de, i.roch@ioer.de.) 